\title{
Characterization of the Grain Structures in Vacuum-Assist High- Pressure Die Casting AM60B Alloy
}

\author{
Xiao-Bo $\mathrm{Li}^{1,2} \cdot$ Shou-Mei Xiong ${ }^{1,2} \cdot$ Zhi-Peng Guo ${ }^{1,2}$
}

Received: 13 January 2016/Revised: 12 April 2016/Published online: 23 May 2016

(C) The Chinese Society for Metals and Springer-Verlag Berlin Heidelberg 2016

\begin{abstract}
The structures in vacuum-assist high-pressure die casting (HPDC) AM60B alloy were studied by using an optical microscope and a scanning electron microscope with an energy dispersive spectrometer. It was found that the HPDC under the vacuum could significantly change the morphology and distribution of the microstructure. For both conventional and vacuum-assist HPDC processes, the externally solidified crystals (ESCs) tended to aggregate in the center along the thickness direction of the castings. Besides, the aggregation was more pronounced, and the number of ESCs decreased, and the ESCs tended to become smaller and more globular, as the distance between the specimen location and runner increased. Compared with the conventional castings, the vacuum-assist HPDC can significantly reduce the size and amount of ESCs, and the ESCs tended to be more globular. For the distribution of ESCs along the thickness of the specimens, the aggregation tendency was more pronounced in vacuum-assist die castings than that in conventional castings. Besides, the distribution of ESCs at different locations was more converged in the vacuum-assist HPDC than that in the conventional HPDC.
\end{abstract}

KEY WORDS: AM60B alloy; Grain structure; Vacuum-assist high-pressure die casting; Externally solidified crystals

\section{Introduction}

As one of the lightest structure materials, the magnesium alloys have been paid more and more attention in recent years in automotive and electronic industries because of their light weight, energy saving, and environmental protection $[1,2]$. Most of the magnesium alloy components are manufactured by high-pressure die casting (HPDC) process

Available online at http://link.springer.com/journal/40195

Zhi-Peng Guo

zhipeng_guo@mail.tsinghua.edu.cn

1 School of Materials Science and Engineering, Tsinghua University, Beijing 100084, China

2 Key Laboratory for Advanced Materials Processing Technology, Ministry of Education, Tsinghua University, Beijing 100084, China due to the advantages of good dimensional accuracy, high production efficiency, and considerable economic benefit.

The HPDC process generally is comprised of pouring, slow shot stage, fast shot stage, and solidification under intensification pressure. The solidification starts immediately when the liquid melt is poured into the shot sleeve due to the fast heat transfer [3]. Crystals nucleate and grow, and subsequently the external solidified crystals (ESCs) create during the slow shot stage. During the fast shot stage, the semisolid melt is injected into the die cavity, and the ESCs could either be remelted because of high superheat transferred from elsewhere or continue to grow because of local undercooling.

A typical microstructure of HPDC magnesium alloy is comprised of $\alpha-\mathrm{Mg}$ grains, ESCs [4], divorced eutectics [5], porosities [6], and defect bands [7, 8]. The ESCs have a significant influence on the microstructure (e.g., the grain size and distribution of segregation bands) and subsequent 
performance of the magnesium components. Cao and Wessen [9] observed that more ESCs formed under lower pouring temperature, and more fragmented dendrites and spherical ESCs formed under higher injection speed. They also found that there were two types of the segregation bands: the first type was determined by the level and magnitude of ESCs present in the die castings, and the second type was less common and found to have no obvious relation with ESCs. Laukli et al. [10] studied the effect of grain refiner on the microstructure of HPDC A356 alloy and found that there were three types of ESCs, including globular crystals, elongated trunks, and dendrites. The area fraction of ESCs increased with the decrease in melt superheat. A lower superheat resulted in coarser and more globular ESCs, while a larger superheat leads to more branched and dendritic ESCs. Effects of the shot speed and biscuit thickness on ESCs of HPDC AM60B alloy were found by Wang and Xiong [11]. It was found that the number of ESCs in die casting decreased with increasing biscuit thickness. Besides, under lower slow shot speed, larger ESCs could be found, and a higher fast shot speed resulted in more spherical ESCs. For the migration of ESCs during filling in HPDC, it was found that: (1) the fraction of ESCs determined the extent of migration to the central region; (2) a maximum packing determined the area fraction of ESCs in the center; and (3) the die temperature affected the position of the ESCs and a higher die temperature could induce a dispersive ESCs distribution [12].

As for the effect of ESCs on the mechanical properties, studies showed that the improved mechanical properties in HPDC could be attributed to the fine uniform microstructures, meaning the decrease in ESCs and elimination of large gas porosities. Ji et al. [13, 14] studied the microstructure and mechanical properties of the rheo-die casting, and found that the fine, uniform microstructure was one of the reasons for the improved mechanical properties, which was similar to the studies conducted by Tzamtzis et al. [15] and Liu et al. [16]. The fatigue crack growth mechanisms for HPDC magnesium alloys were studied by Kadiri [17], and the result showed that the fatigue micromechanisms were related to the concomitant effects of casting pores, interdendritic Al-rich solid solution layer, $\beta$-phase particles, Mn-rich inclusions, rare earthrich intermetallics, dendrite cell size, and surface segregation. Jiang et al. [18-20] found that the high pressure caused by forging system in double control forming process resulted in obvious grain refinement of the primary $\alpha$ $\mathrm{Mg}$ and uniform distribution of the eutectic, which contributed to the higher mechanical properties in comparison with die castings.

As a new casting process, the vacuum-assist HPDC process has been studied in many aspects, in particular its effects on the porosity $[21,22]$ and mechanical properties [23-26], but little attention has been paid to its effect on the microstructure of the components. In this paper, the effect of vacuum on the microstructure in particular the grain structure in HPDC AM60B alloy was presented. It was shown that under vacuum-assist, the filling process as well as the heat transfer inside both sleeve and die cavity could be altered, which subsequently generated significant influence on the microstructure transition during solidification.

\section{Experiment}

In this study, a specific casting, namely "crash box" (Fig. 1) with a wall thickness of $2.5 \mathrm{~mm}$ was produced by using a TOYO BD-350V5 cold chamber die casting machine. The key parameters adopted during conventional and vacuum-assist HPDC processes were the same, which are given in Table 1. The composition of the commercial AM60B magnesium alloy used in experiment is given in Table 2. The solidus and liquidus temperatures of the AM60B alloy are 540 and $615^{\circ} \mathrm{C}$, respectively.

A ZEISS scope A1 optical microscope (OM) and a Hitachi S-4500 scanning electron microscope (SEM) with an energy dispersive spectrometer (EDS) were used to

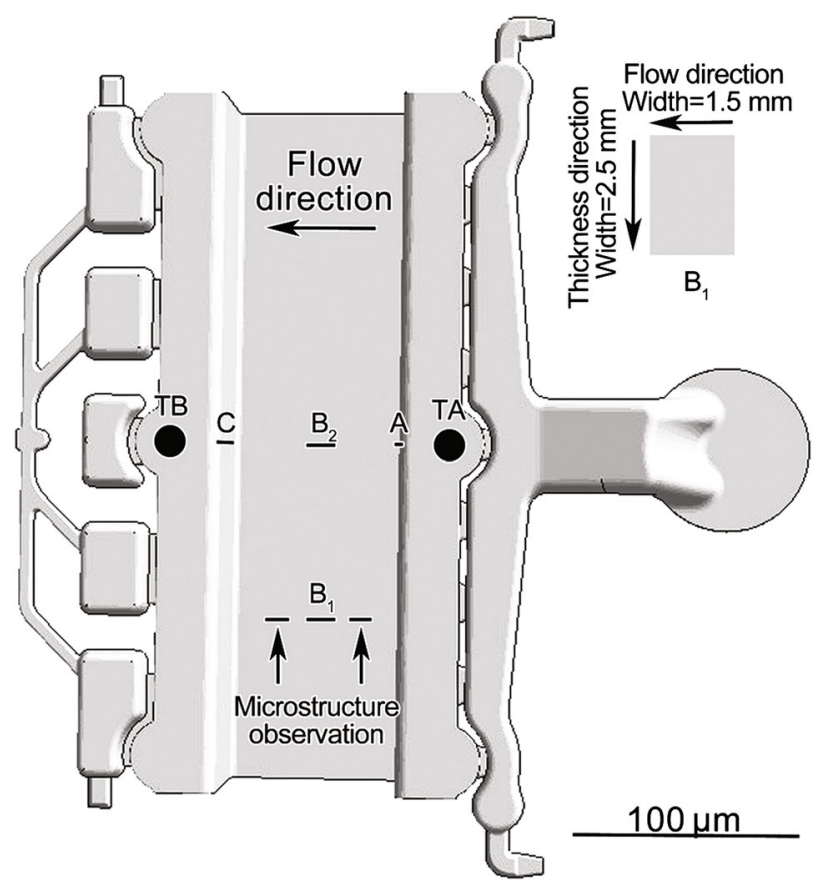

Fig. 1 Configuration of the "crash box" casting. The samples for microstructure analysis were extracted at locations $A, B_{1}, B_{2}$, and $C$, the microstructure observation area of location $\mathrm{B}_{1}$ (also the locations $\mathrm{A}, \mathrm{B}_{2}$, and $\mathrm{C}$ ) was shown in the upper right corner. The interfacial heat transfer analysis was conducted at locations TA and TB 
Table 1 Key parameters adopted during conventional and vacuum-assist HPDC processes

\begin{tabular}{lllll}
\hline Pouring temperature $\left({ }^{\circ} \mathrm{C}\right)$ & Initial mold temperature $\left({ }^{\circ} \mathrm{C}\right)$ & Casting pressure $(\mathrm{MPa})$ & Slow shot velocity $(\mathrm{m} / \mathrm{s})$ & Fast shot velocity $(\mathrm{m} / \mathrm{s})$ \\
\hline 680 & 180 & 87 & 0.2 & 2.5 \\
\hline
\end{tabular}

Table 2 Chemical compositions of the AM60B magnesium alloy used in the study (mass\%)

\begin{tabular}{|c|c|c|c|c|c|c|}
\hline $\mathrm{Al}$ & $\mathrm{Mn}$ & $\mathrm{Zn}$ & $\mathrm{Si}$ & $\mathrm{Cu}$ & $\mathrm{Fe}$ & $\mathrm{Mg}$ \\
\hline 5.9 & 0.31 & 0.16 & 0.06 & 0.007 & 0.003 & $\mathrm{Bal}$ \\
\hline
\end{tabular}

observe and analyze the microstructure evolution of the specimens at different locations of the conventional and vacuum-assist HPDC crash boxes. The metallographic specimens were extracted at locations of $\mathrm{A}, \mathrm{B}_{1}, \mathrm{~B}_{2}$, and $\mathrm{C}$, and the microstructure observation area of location $\mathrm{B}_{1}$ (also the locations $\mathrm{A}, \mathrm{B}_{2}$, and $\mathrm{C}$ ) is shown in the upper right corner in Fig. 1. All of the metallographic specimens were etched with a diluted acetic acid solution, which is comprised of $50 \mathrm{~mL}$ distilled water, $150 \mathrm{~mL}$ anhydrous ethyl alcohol, and $1 \mathrm{~mL}$ glacial acetic acid. Software Microimage Analysis and Process System (MIAPS) was employed to perform the quantitative analysis of the ESCs area fraction (i.e., the area occupied by the ESCs divided by the whole area of the specimen in interest) and average diameter (i.e., the diameter of an equivalent circle, which had the same area as that occupied by the ESCs).

In both conventional and vacuum-assist HPDC processes, the temperature measurement experiment was carried out at the locations near gate (TA) and far from gate (TB) of the crash box as shown in Fig. 1. The temperature measurement program was consistent with the literature [27]. Based on the temperature profiles obtained at different locations inside the die during conventional and vacuum-assist HPDC processes, the interfacial heat transfer coefficient (IHTC) between the melt and die wall and the cooling curves of the melt in surface layer were determined by employing the nonlinear estimation method $[28,29]$.

\section{Results and Discussion}

\subsection{Typical Grain Structures}

As shown in Fig. 2, the typical microstructure of HPDC AM60B alloy is comprised of $\alpha-\mathrm{Mg}$ grains, ESCs, eutectics, and porosity, which was similar to the literature [20]. The $\alpha$-Mg grains, nucleated and grew up in die cavity, were small globular and widely distributed in the specimen. As

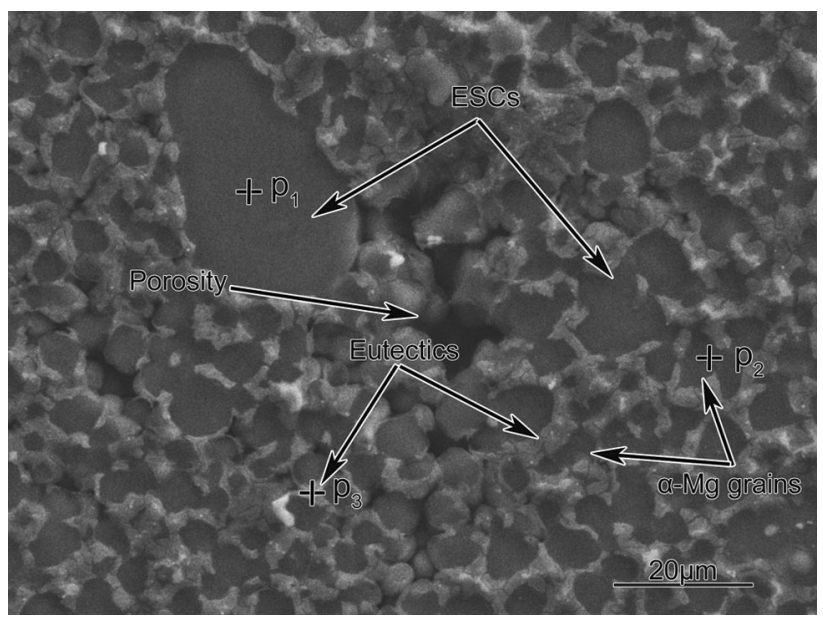

Fig. 2 A typical microstructure at location $\mathrm{A}$ of the conventional HPDC crash box $\left(\mathrm{P}_{1}, \mathrm{P}_{2}\right.$, and $\mathrm{P}_{3}$ were marked as the locations where the EDS analysis was performed)

discussed in the literature [10], the ESCs nucleated in shot sleeve and grew up in both shot sleeve and die cavity were large globular or dendritic, which were surrounded by $\alpha$ $\mathrm{Mg}$ grains. EDS analysis was conducted at locations of $\mathrm{P}_{1}$, $\mathrm{P}_{2}$, and $\mathrm{P}_{3}, \mathrm{P}_{1}$ were inside an ESC; $\mathrm{P}_{2}$ was inside an $\alpha-\mathrm{Mg}$ grain; and $\mathrm{P}_{3}$ was inside the eutectic. The EDS results listed in Table 3 indicated that the $\mathrm{Al}$ content in ESCs was much lower than that in $\alpha-\mathrm{Mg}$ grains, and was the highest in eutectics. In order to avoid the randomness of EDS results, the compositions of another five ESCs, five $\alpha-\mathrm{Mg}$ grains, and five eutectics were also analyzed, and the composition ranges of the ESCs, $\alpha-\mathrm{Mg}$ grains, and eutectic are listed in Table 3, which confirmed the above EDS results of points $\mathrm{P}_{1}, \mathrm{P}_{2}$, and $\mathrm{P}_{3}$.

The higher $\mathrm{Al}$ content in both $\alpha-\mathrm{Mg}$ grains and eutectics can be explained by the solidification sequence in HPDC because the melt temperature was the highest when it poured into the shot sleeve, and cooled down during casting process. According to the phase diagram [30], the earliest solidified ESCs had the minimum Al content, whereas the subsequent solidified $\alpha-\mathrm{Mg}$ grains and eutectics had a higher $\mathrm{Al}$ content.

Figure $3 \mathrm{a}, \mathrm{b}$ shows the typical microstructures on the surface layer (i.e., closest to the die cavity surface) at location A of the conventional HPDC crash box. There were a few small globular ESCs surrounded by a large number of fine $\alpha-\mathrm{Mg}$ grains, and no large dendritic ESCs 
Table 3 Quantity of elements according to EDS analysis (mass\%)

\begin{tabular}{lllllll}
\hline Position & $\mathrm{P}_{1}$ & $\mathrm{P}_{2}$ & $\mathrm{P}_{3}$ & ESCs & $\alpha$-Mg grains \\
\hline $\mathrm{Mg}$ & 98.04 & 95.48 & 79.70 & $97.76-100$ & $95.61-92.50$ & $68.96-82.34$ \\
$\mathrm{Al}$ & 1.96 & 4.52 & 20.30 & $0-2.24$ & $4.39-7.50$ & $17.66-27.71$ \\
$\mathrm{Mn}$ & 0 & 0 & 0 & 0 & 0 & $0-3.34$ \\
\hline
\end{tabular}
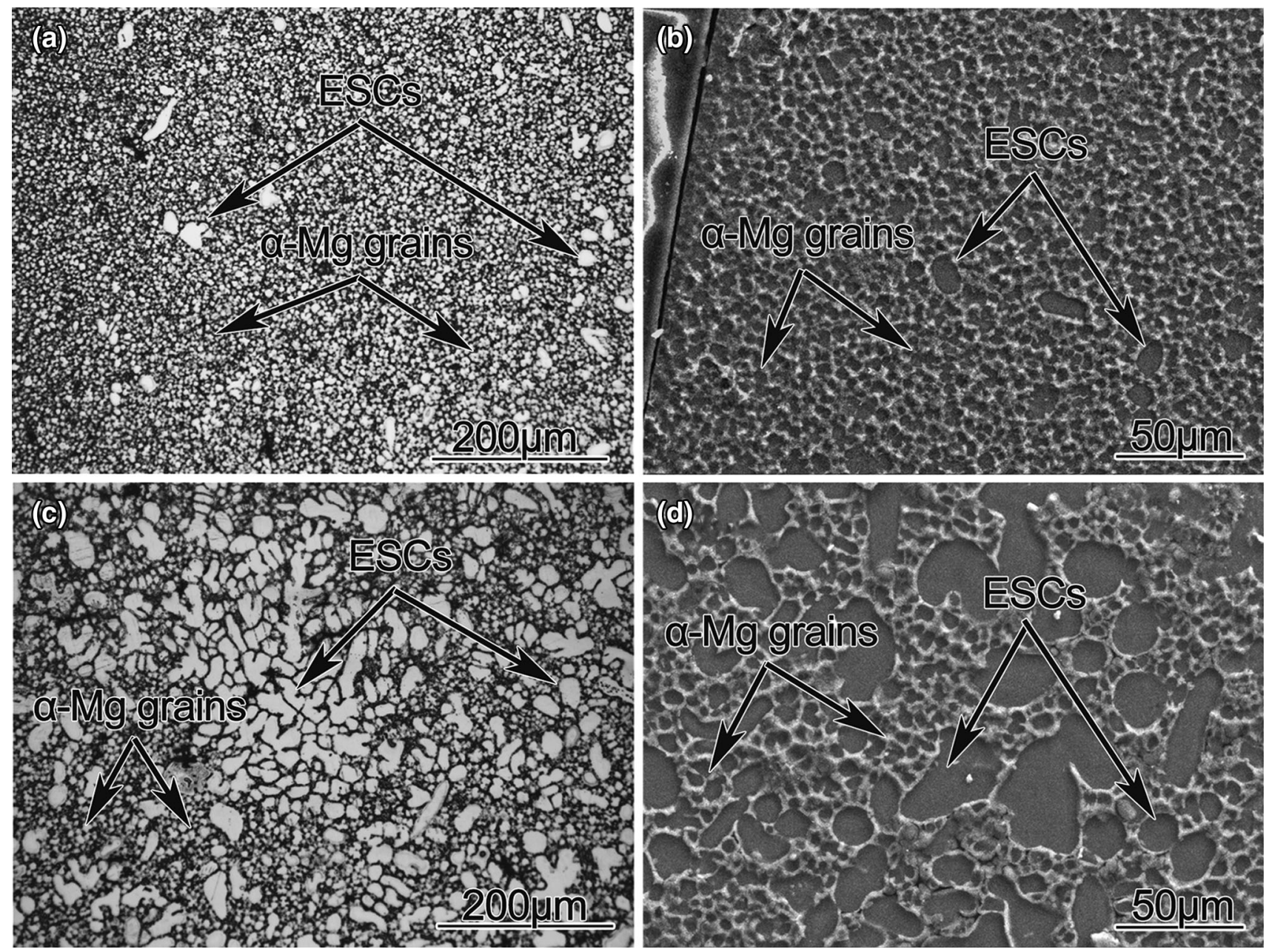

Fig. 3 Comparison of the microstructures between the surface layer (top row) and the center (bottom row) at location A of the conventional HPDC crash box: a, c OM, b, d SEM

could be observed. However, in the center at location A of the crash box, as shown in Fig. 3c, d, both large dendritic and small globular ESCs could be observed.

Between the surface layer and center of the specimen, there was great difference in shear stress and cooling rate in the melt during filling and solidification processes. Under high injection speed, the ESCs tended to be more fragmented dendrites and spherical $[9,11]$. On the other hand, the grain refinement can be achieved by a rapid cooling [30]. For a Newtonian fluid, the shear stress is proportional to velocity gradient. Because the velocity gradient on the surface layer was higher, the shear stress on surface layer was larger than that in center of the specimen. Under the higher shear stress, the ESCs on surface layer were more likely to be broken or dissolved. Furthermore, because of the higher IHTC between the melt and die, the cooling rate on surface layer was much higher than that in the center, leading to more $\alpha-\mathrm{Mg}$ grains, which inhibited the further growth of ESCs in die cavity. Consequently, larger and more dendritic ESCs existed in the center of the specimen, 
while smaller and more globular ESCs existed on the surface layer of the specimen.

The microstructure at different locations of the conventional HPDC crash box is shown in Fig. 4. It can be observed that the ESCs tended to become smaller and more globular, as the distance between the sample location and runner increased.

The difference of the microstructures at different locations can be understood by examining the filling and solidification sequences. Because location $\mathrm{A}$ was the nearest to the runner, the melt solidified at location $\mathrm{A}$ had previously stayed a longer time in shot sleeve, leading to higher possibility of nucleation and growth of ESCs. On the other hand, because location $\mathrm{C}$ was the farthest from the runners, the ESCs that arrived and solidified at location $\mathrm{C}$ would bear shear stress for a longer time during the filling process, and were thus more likely to be broken or dissolved before they reach location C. Furthermore,
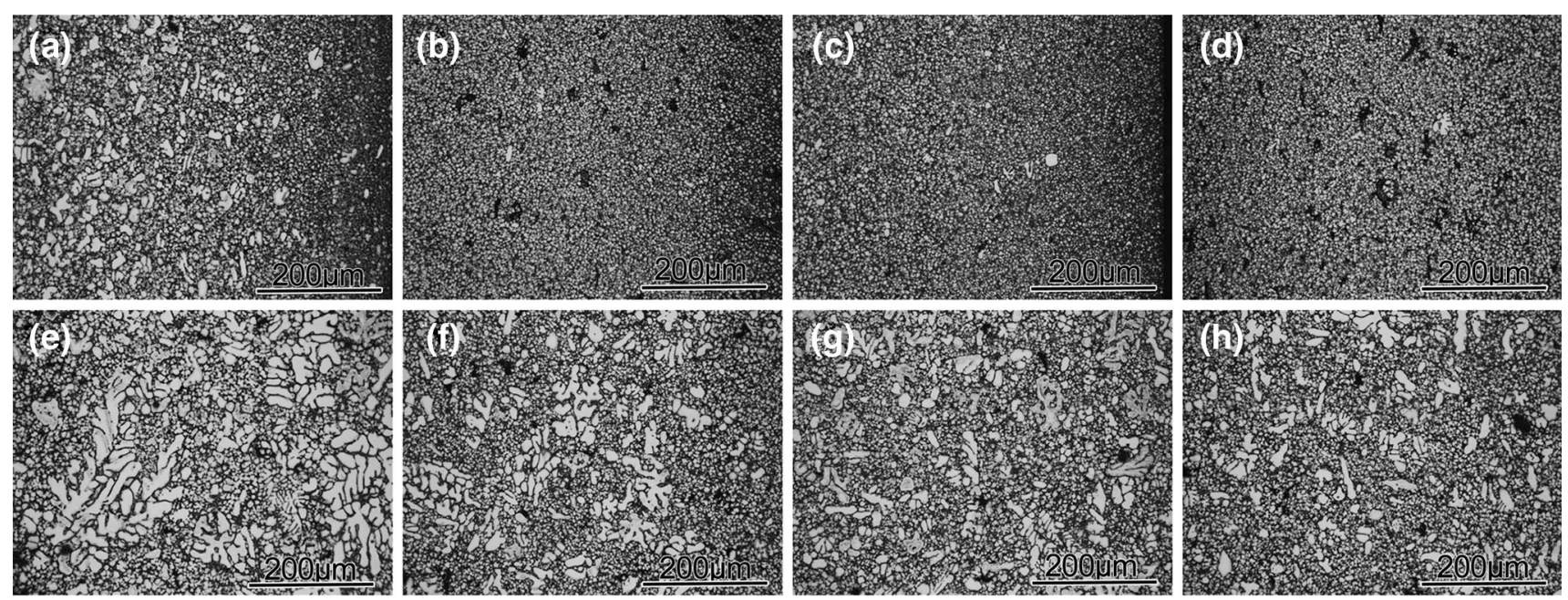

Fig. 4 Comparison of the microstructures between the surface layer (top tow) and the center (bottom row) of the conventional HPDC crash box. From left to right, each column of the figures shows the microstructures at locations $\mathrm{A}, \mathrm{B}_{1}, \mathrm{~B}_{2}$, and $\mathrm{C}$ (see Fig. 1), respectively
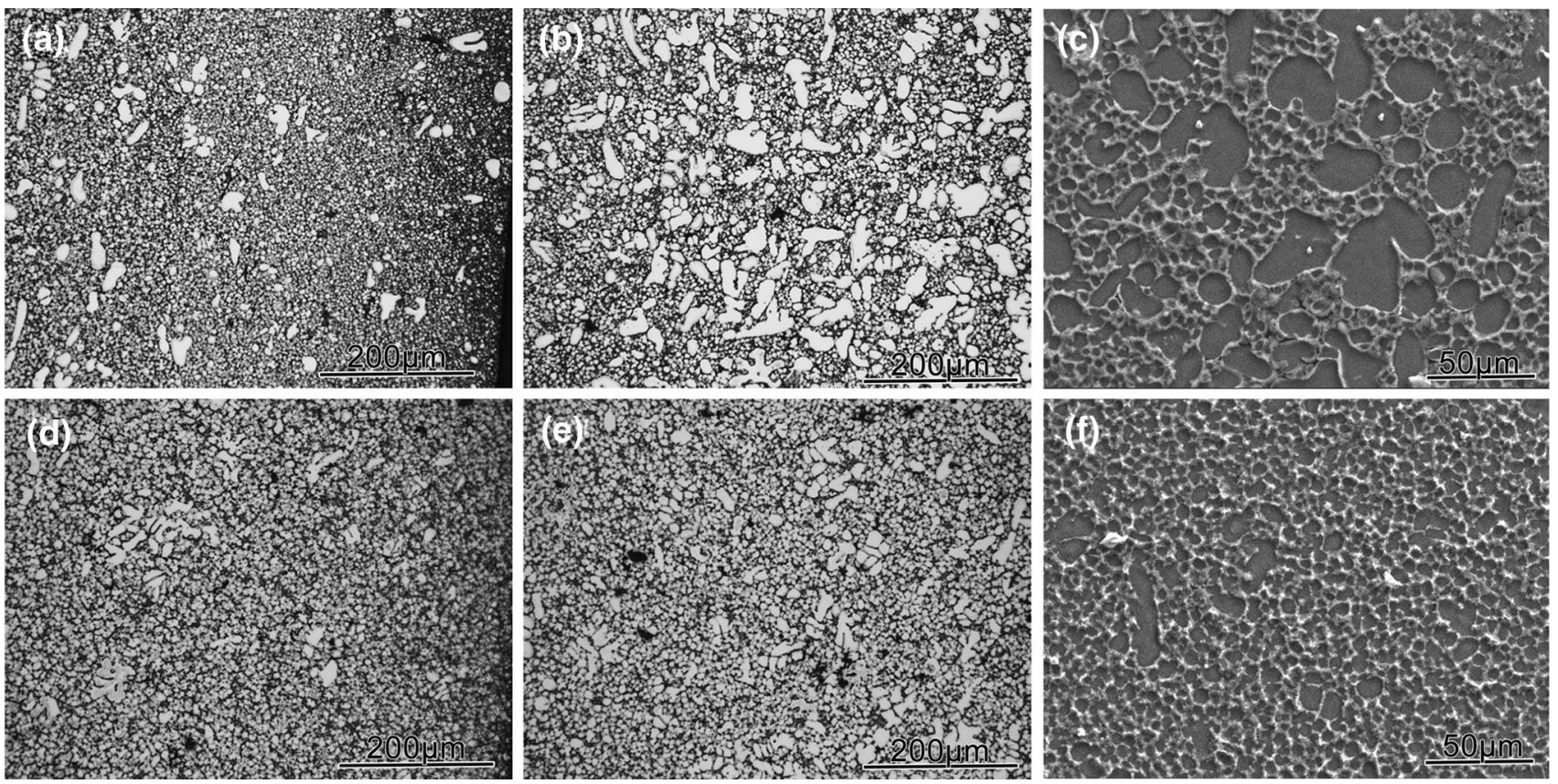

Fig. 5 Comparison of the microstructures at location A of the conventional (top row) and vacuum-assist (bottom row) HPDC crash boxes: a, $\mathbf{d}$ the microstructures in the surface layer, $\mathbf{b}, \mathbf{c}, \mathbf{e}, \mathbf{f}$ the microstructures in the center of the samples 
during the filling process, a solidified layer near the die wall would create due to the fast cooling, and some of these nuclei previously existing in the solidified layer would be carried to the further end of the die cavity, e.g., location C, due to the melt flow. As a consequence, smaller and more globular ESCs, as well as larger $\alpha-\mathrm{Mg}$ grains existed at location C (see Fig. 4d, h), whereas larger and more dendritic ESCs existed at location A (see Fig. 4a, e).

\subsection{Effect of Vacuum on Grain Structures}

Figure 5 shows the microstructures at location A in conventional (top row) and vacuum-assist (bottom row) HPDC crash boxes. Compared with the conventional HPDC, the vacuum-assist HPDC significantly reduced the size and amount of ESCs, thus leading to more globular.

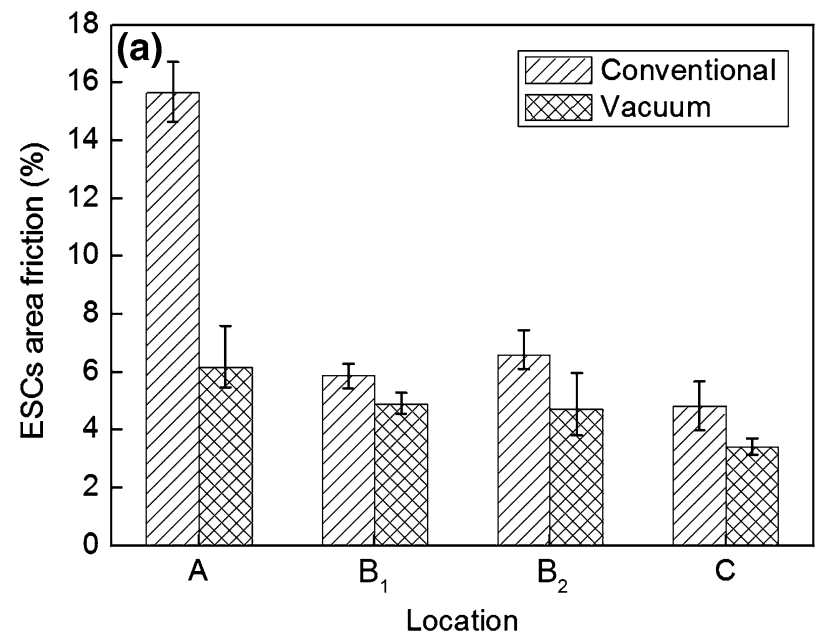

To achieve a better understanding on the effect of vacuum, quantitative analysis of the ESCs average diameter and area fraction for all locations of the conventional and vacuum-assist HPDC crash boxes was performed. The results are shown in Fig. 6. At each location, four samples with an area of $2.5 \mathrm{~mm} \times 1.5 \mathrm{~mm}$ were considered (see Fig. 1). As shown in Fig. 6, both the area fraction and average diameter of the ESCs at each location were reduced under vacuum-assist HPDC.

As shown in Fig. 7a, the maximum IHTC was lager in vacuum-assist HPDC than that in conventional HPDC at either TA or TB, which confirmed the deduction in study conducted by Wei et al. [25], who found that the skin layer in vacuum die castings was harder and thicker than that in conventional die castings. This is because under the vacuum-assist, there was little air left in die cavity. As the

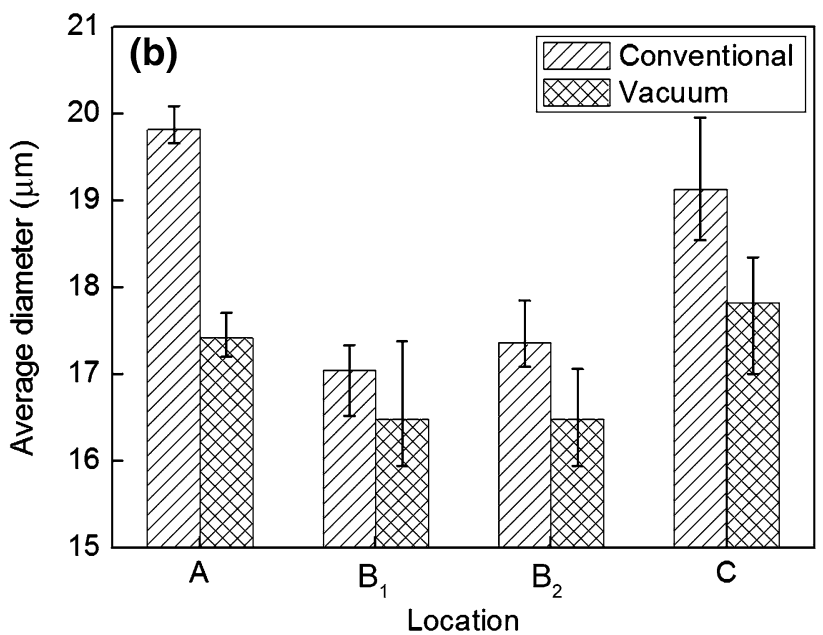

Fig. 6 Comparison of a the area fraction, $\mathbf{b}$ average diameter of ESCs at different locations of the conventional and vacuum-assist HPDC crash boxes
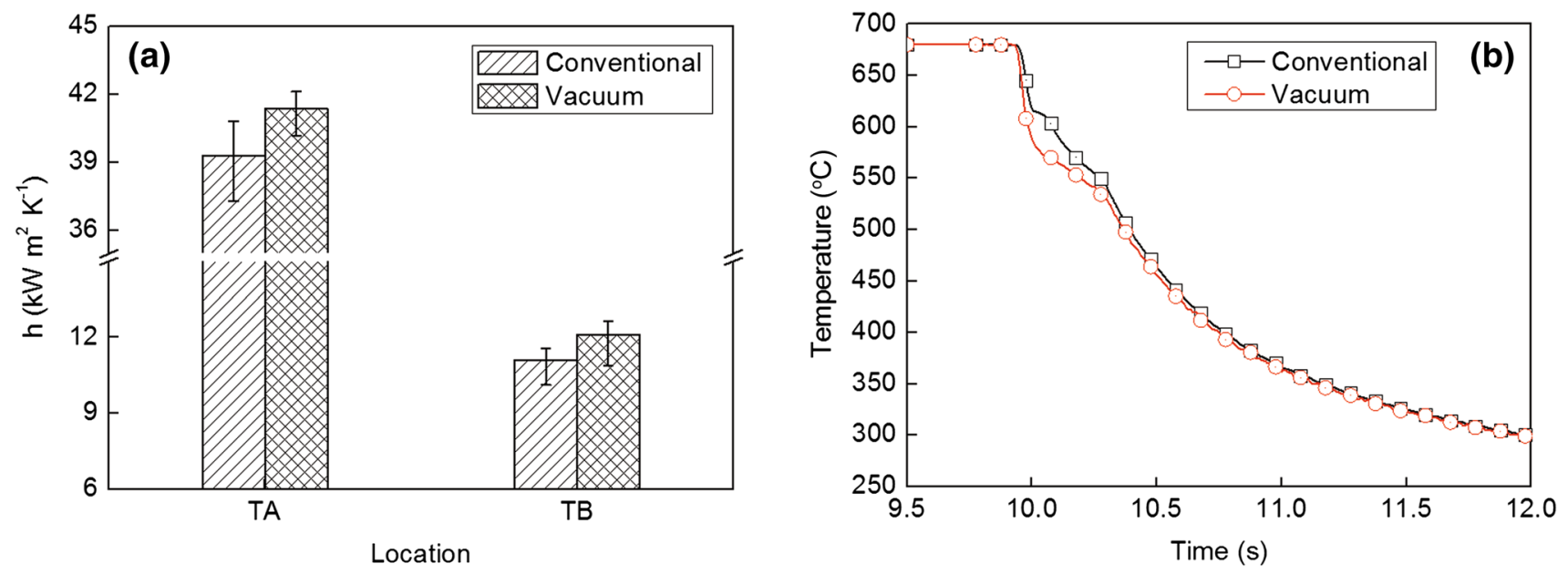

Fig. 7 Comparison of a the peak values of IHTC, $\mathbf{b}$ the melt surface temperature under conventional and vacuum-assist HPDC processes 

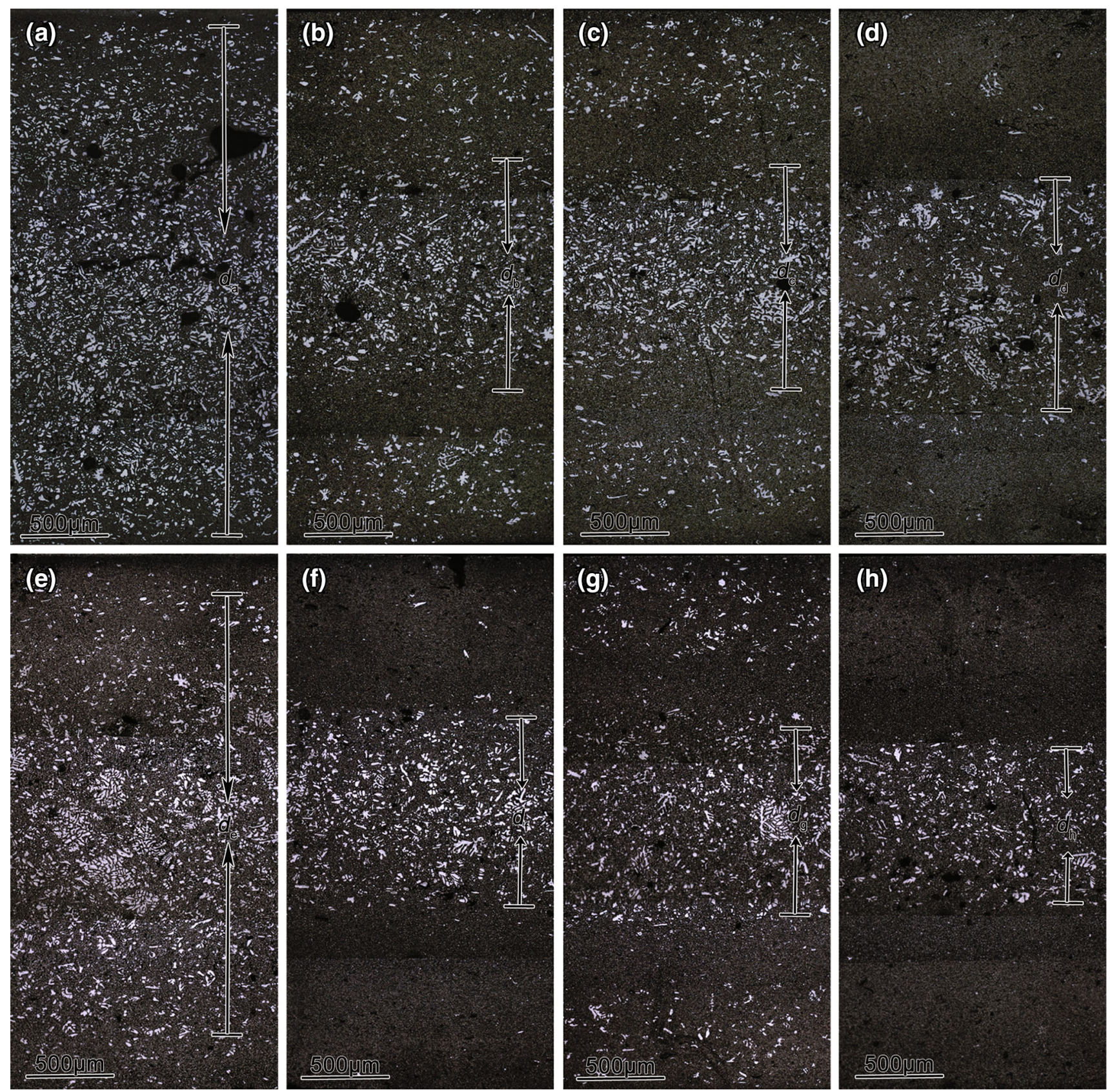

Fig. 8 Comparison of the microstructure of the cross section at different locations. From left to right, each column of images correspond to locations $\mathrm{A}, \mathrm{B}_{1}, \mathrm{~B}_{2}$, and $\mathrm{C}$ of conventional (top row) and vacuum-assist (bottom row) HPDC crash boxes

filling process started, the reduction of the air led to closer contact between the melt and die wall because of the reduced surface tension on the melt surface. As a result, an improved heat transfer could be achieved and maintained on the melt surface in the vacuum-assist HPDC crash box, leading to a lower surface temperature (see Fig. 7b) and a thicker solidified surface layer during the filling process. Because the air in gas pores was an efficient heat-insulation medium, it retarded heat transfer in the melt [31]. Under the vacuum-assist, the porosity area fraction (i.e., the area occupied by the porosity divided by the whole area of the specimen in interest) of the location $\mathrm{A}$ in conventional die castings $(2.4 \%)$ was reduced to $0.4 \%$ in vacuum die castings. Thus, the heat transfer inside the melt and subsequent cooling rate in vacuum-assist HPDC could be strengthened. With higher cooling rate, the nucleation and growth rate of $\alpha-\mathrm{Mg}$ grains in vacuum-assist HPDC were much higher than those in conventional HPDC, thereby inhibiting the further growth of ESCs in die cavity, leading to a microstructure with more $\alpha$-Mg grains and less ESCs. 


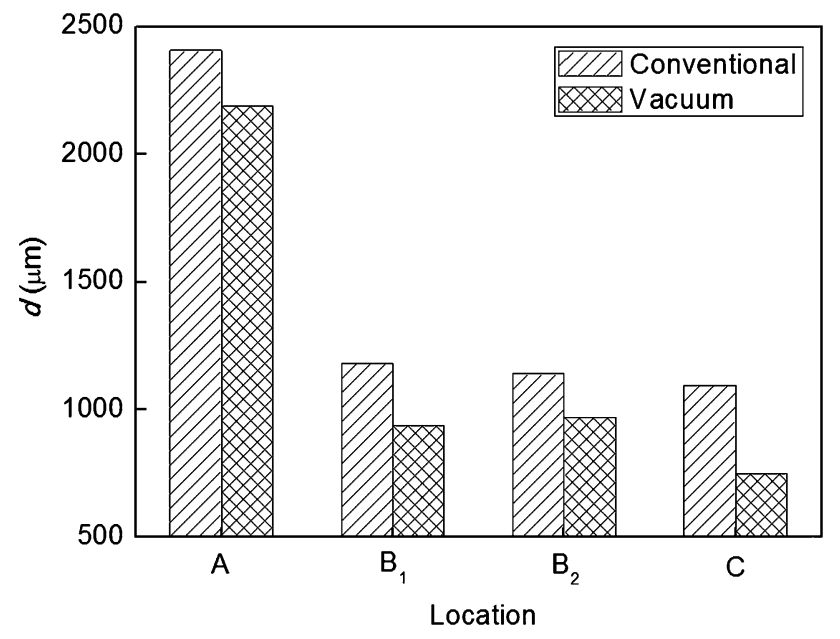

Fig. 9 Comparison of the aggregation tendency, $d$ at different locations of the conventional and vacuum-assist HPDC crash boxes

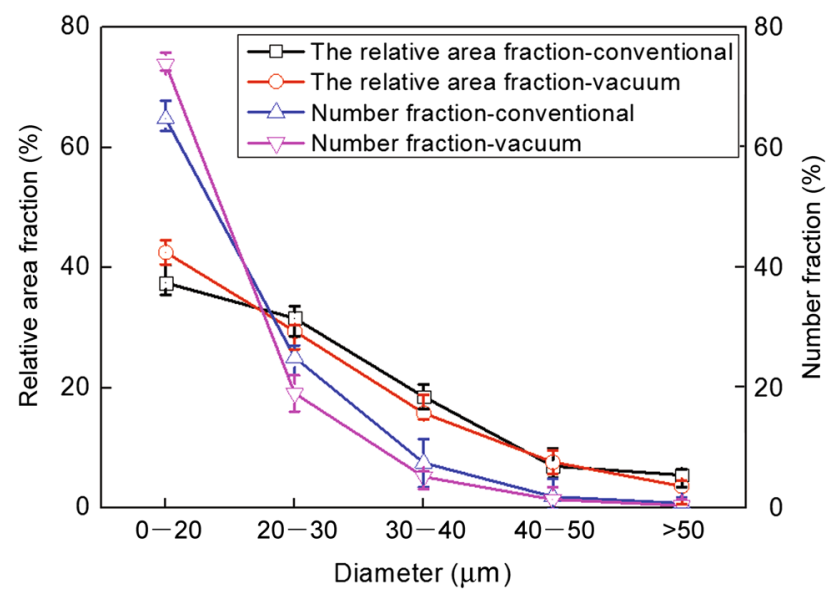

Fig. 10 Relative area friction and number fraction of ESCs as a function of the ESC diameter at the location A of the conventional and vacuum-assist HPDC crash boxes

\subsection{Effect of Vacuum on the ESC Distribution}

The microstructures of the cross section at different locations of the conventional and vacuum-assist HPDC crash boxes are shown in Fig. 8. In both cases, the ESCs tended to be aggregated in the center of the specimens, which was consistent with the result of Laukli et al. [12]. A width, as designated by $d$, was used to measure the aggregation tendency of ESCs in the center of the specimens, as shown in Fig. 9. In both conventional and vacuum-assist HPDC processes, the aggregation of ESCs was more pronounced, and $d$ was smaller, if the specimen location was further from the runner. Besides, the aggregation was more pronounced in vacuum-assist HPDC than that in conventional HPDC.

Figure 10 shows the number fraction and relative area fraction of ESCs as a function of the ESC diameter at location $\mathrm{A}$ of the conventional and vacuum-assist HPDC crash boxes. The number fraction is the number of ESCs with a specific diameter divided by the total number of ESCs, while the relative area fraction is the area occupied by the ESCs with a specific diameter divided by the whole area occupied by the ESCs. It can be observed that both the number fraction and relative area fraction decreased with increasing ESC diameter in both conventional and vacuumassist HPDC crash boxes, and the decreasing tendency in vacuum-assist HPDC crash box was more pronounced than that in conventional HPDC crash box. Additionally, the growth of ESCs was highly inhibited in vacuum-assist HPDC process, leading to relatively smaller ESCs than those in conventional HPDC crash box.

The area fractions of ESCs as a function of normalized thickness at different locations of conventional and vacuum-assist HPDC crash boxes are shown in Fig. 11. Accordingly, two results can be observed as follows:

1. For both conventional and vacuum-assist HPDC crash boxes, the area fraction of ESCs all decreased from locations $\mathrm{A}, \mathrm{B}_{2}, \mathrm{~B}_{1}$, to $\mathrm{C}$, and the ESCs tended to aggregate in the center at all locations of crash boxes;

2. The distribution of ESCs at different locations was more converged in the vacuum-assist HPDC than that in the conventional HPDC.

As discussed, because of the higher IHTC, the enhanced surface chilling effect would lead to a thicker skin layer, and thus, the aggregation tendency of ESCs in the center of the vacuum-assist HPDC was more pronounced (Fig. 8). On the other hand, the ESCs would become smaller and more globular in vacuum-assist HPDC crash box because more $\alpha-\mathrm{Mg}$ grains were present (i.e., further growth of the ESCs were retarded).

The distribution of ESCs was mainly determined by the filling process. In conventional HPDC, the filling process was much more complex than that in vacuum-assist HPDC. During filling process in conventional HPDC, three phases including liquid (melt), solid (ESCs), and gas (air) were present in the melt, and both gas entrapment and discharge existed. The gas discharge capacity was mainly determined by the exhaust valve, casting structure, melt temperature, and melt filling pressure. The porosity area fractions of the locations $\mathrm{A}, \mathrm{B}_{1}, \mathrm{~B}_{2}$, and $\mathrm{C}$ in conventional HPDC crash box were $2.4 \%, 0.5 \%, 0.4 \%$, and $0.8 \%$, respectively, which implied that the filling conditions, especially the gas entrapment, were different at different locations of conventional HPDC crash box, leading to different flow and temperature fields, and consequently a more divergent pattern of the ESC distribution could be achieved (Fig. 11a)whereas, in vacuum-assist HPDC, little air was present in die cavity when the filling process started, which enhanced the gas discharge. As a result, the porosity area 

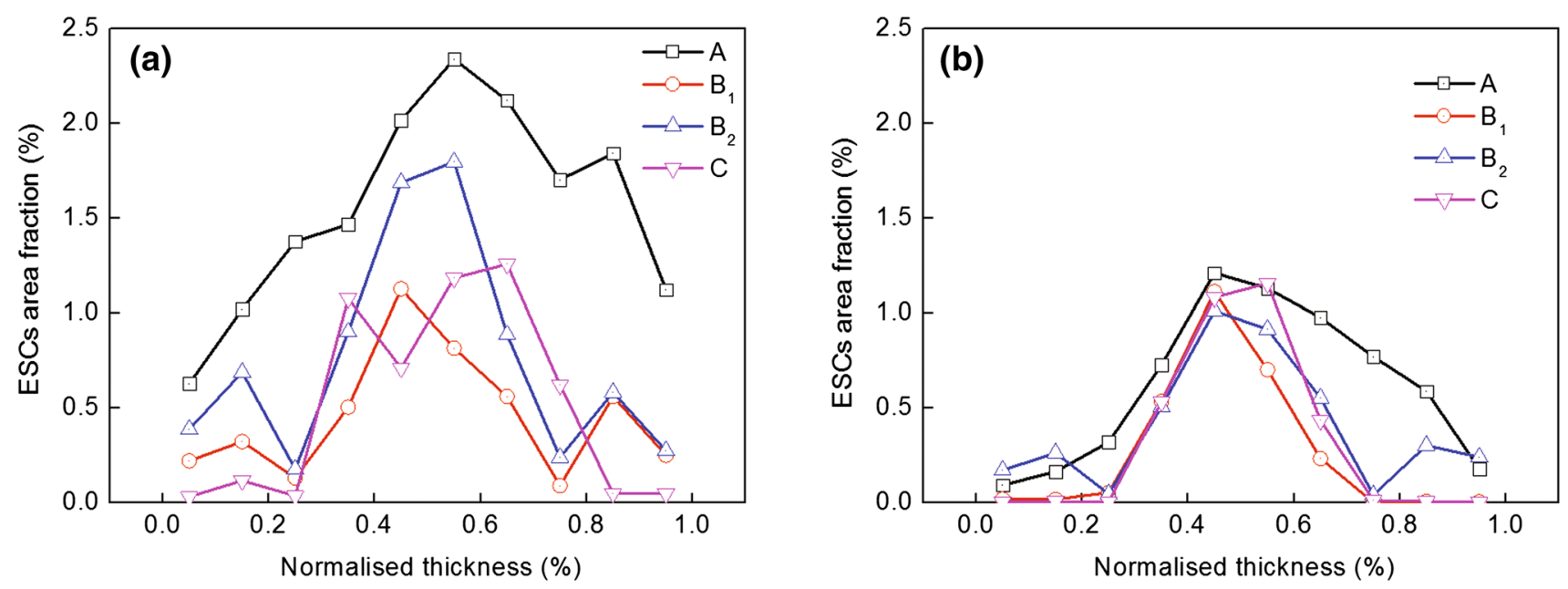

Fig. 11 Area fraction of ESCs as a function of the normalized thickness at different locations of a conventional, b vacuum-assist HPDC crash boxes

fractions of the locations $\mathrm{A}, \mathrm{B}_{1}, \mathrm{~B}_{2}$, and $\mathrm{C}$ were reduced to $0.4 \%, 0.3 \%, 0.1 \%$, and $0.3 \%$, respectively. Thus, there were less gas entrapment and more homogeneous filling conditions (including flow and temperature fields) at different locations. Therefore, the ESC distributions at different locations of the vacuum-assist HPDC crash box were more converged than those of the conventional HPDC crash box (Fig. 11b).

\section{Conclusions}

1. For both conventional and vacuum-assist HPDC processes, the ESCs tended to be aggregated in the center along the thickness direction of the castings. Besides, the aggregation was more pronounced, and the number of ESCs decreased, as well as the ESCs tended to become smaller and more globular, as the distance between the sample location and runner increased.

2. Compared with the conventional HPDC, the vacuumassist HPDC significantly reduced the size and amount of ESCs, and made the morphology of ESCs tend to be more globular.

3. For the distribution of ESCs, the aggregation tendency was more pronounced in vacuum-assist die castings than that in conventional die castings. Besides, the distribution of ESCs at different locations was more converged in the vacuum-assist HPDC than that in the conventional HPDC.

Acknowledgments The authors gratefully acknowledge the financial support of the National Science and Technology Major Project of the Ministry of Science and Technology of China (Grant No. 2012ZX04012011), the National Natural Science Foundation of
China (Grant No. 51275269), and the Independent Research Program of Tsinghua University (Grant No. 20121087918).

\section{References}

[1] H. Friedrich, S. Schumann, J. Mater. Process. Technol. 117, 276 (2001)

[2] B.L. Mordike, T. Ebert, Mater. Sci. Eng. A 302, 37 (2001)

[3] R. Helenius, O. Lohne, L. Arnberg, H.I. Laukli, Mater. Sci. Eng. A 413-414, 52 (2005)

[4] M.W. Wu, S.M. Xiong, Acta Metall. Sin. 46, 1534 (2010) (in Chinese)

[5] M.W. Wu, S.M. Xiong, J. Mater. Sci. Technol. 27, 1150 (2011)

[6] W.L. Xiao, S.M. Zhu, M.A. Easton, M.S. Dargusch, M.A. Gibson, J.F. Nie, Mater. Charact. 65, 28 (2012)

[7] S. Otarawanna, C.M. Gourlay, H.I. Laukli, A.K. Dahle, Mater. Charact. 60, 1432 (2009)

[8] A.K. Dahle, Y.C. Lee, M.D. Nave, P.L. Schaffer, D.H. Stjohn, J. Light Metals 1, 99 (2001)

[9] H. Cao, M. Wessen, Int. J. Cast Metals Res. 18, 377 (2005)

[10] H.I. Laukli, L. Arnberg, O. Lohne, Int. J. Cast Metals Res. 18, 65 (2005)

[11] B.S. Wang, S.M. Xiong, Trans. Nonferrous Met. Soc. China 21, 767 (2011)

[12] H.I. Laukli, C.M. Gourlay, A.K. Dahle, Metall. Mater. Trans. A 36, 805 (2005)

[13] S. Ji, Z. Zhen, Z. Fan, Mater. Sci. Technol. 21, 1019 (2005)

[14] S. Ji, W. Yang, B. Jiang, J.B. Patel, Z. Fan, Mater. Sci. Eng. A 566, 119 (2013)

[15] S. Tzamtzis, H. Zhang, N.H. Babu, Z. Fan, Mater. Sci. Eng. A 527, 2929 (2010)

[16] Y.Q. Liu, Q. Ma, Z. Fan, Mater. Trans. 46, 2221 (2005)

[17] H. El Kadiri, M.F. Horstemeyer, J.B. Jordon, Y.B. Xue, Metall. Mater. Trans. A 39, 190 (2008)

[18] J.F. Jiang, G. Chen, Y. Wang, Z.M. Du, W.W. Shan, Y.F. Li, J. Alloys Compd. 552, 44 (2013)

[19] J.F. Jiang, Y. Wang, G. Chen, J. Liu, Y.F. Li, S.J. Luo, Mater. Des. 40, 541 (2012)

[20] J.F. Jiang, Y. Wang, Y.F. Li, W.W. Shan, S.J. Luo, Mater. Des. 37, 202 (2012) 
[21] X.P. Niu, B.H. Hu, I. Pinwill, H. Li, J. Mater. Process. Technol. 105, $119(2000)$

[22] X. Li, S.M. Xiong, Z. Guo, J. Mater. Sci. Technol. 32, 54 (2016)

[23] F. Wang, J. Li, J. Liu, D. Lv, P. Mao, Z. Liu, Acta Metall. Sin. (Engl. Lett.) 27, 609 (2014)

[24] J. Song, S.M. Xiong, M. Li, J. Allison, Mater. Sci. Eng. A 520, 197 (2009)

[25] W. Wen, A.A. Luo, T.G. Zhai, Y. Jin, Y.T. Cheng, I. Hoffmann, Scr. Mater. 67, 879 (2012)

[26] L. Wan, Z.Q. Hu, S.S. Wu, X.Q. Liu, Mater. Sci. Eng. A 576, $252(2013)$
[27] Z.P. Guo, S.M. Xiong, S.H. Cho, J.K. Choi, Acta Metall. Sin. 43, 1149 (2007) (in Chinese)

[28] Z.P. Guo, S.M. Xiong, S.H. Cho, J.K. Choi, Acta Metall. Sin. 43, 607 (2007) (in Chinese)

[29] Z.P. Guo, S.M. Xiong, B.C. Liu, M. Li, J. Allison, Metall. Mater. Trans. A 39, 2896 (2008)

[30] A.K. Dahle, Y.C. Lee, M.D. Nave, P.L. Schaffer, D.H. StJohn, J. Light. Metals 1, 61 (2001)

[31] S.G. Lee, A.M. Gokhale, Scr. Mater. 55, 387 (2006) 